\title{
Specifications and Standards for the Electric Warship
}

\author{
Dr. Norbert Doerry \\ Naval Sea Systems Command \\ United States Navy \\ Washington DC, USA \\ norbert.doerry@navy.mil
}

\author{
Khosrow Moniri \\ Naval Sea Systems Command \\ United States Navy \\ Washington DC, USA \\ khosrow.moniri@navy.mil
}

\begin{abstract}
The U.S. Navy has invested considerable funds in the research and development of electrical power technologies for future electric warships. One aspect of institutionalizing these technologies is the creation or modification of standards and specifications to incorporate the new technologies. This paper assesses the current state of standards and specifications in support of the design and construction of an all-electric naval warship. These technical documents will be evaluated in terms of the different power systems architectures to include low voltage ac generation, medium voltage ac generation, medium voltage de generation, and zonal power distribution. Ongoing standards activity, both in industry and in the Navy, are discussed. Finally, the paper presents recommendations for updating existing specifications and standards and the creation of new specifications to cover technical areas where standards do not currently exist.
\end{abstract}

\section{INTRODUCTION}

Naval warships are increasingly becoming more electric. The electrification of the warship is driven by the need to support the electrical power demands of advanced weapons and combat systems as well as in the move towards electric propulsion to reduce fuel consumption and the move to electric auxiliaries to reduce total ownership costs. While historically, shipboard power systems have employed low voltage (450 volts ac) for power generation and distribution, higher power levels and the need for improved reliability (quality of service) and survivability have led to the introduction of medium voltage ac (MVAC), and medium voltage dc (MVDC) systems into the fleet. To reduce the weight and cost of distribution cabling, larger warships have incorporated zonal distribution systems (ZEDS) instead of the more traditional radial distribution systems.

These changes in power system technologies require an extensive updating of standards, specifications, handbooks, and guides that comprise the electric warship technical architecture. This paper describes ongoing and future projects to create or update standards and specifications to support future electric warship acquisitions. To organize the discussion, the technical architecture will be discussed in terms of the different electric system functions as defined for the Integrated Power System in [1]:
- System Design and Engineering design and integrate power systems.

- Power Generation convert fuel to electrical power.

- Power Distribution consist of switchgear and cabling necessary to distribute the power.

- Power Conversion convert power from one voltage /frequency to another.

- Energy Storage store energy provided by and provided to the electrical power system.

- Loads use electrical power.

- Propulsion Motors and Drives convert electrical power into propulsion for the ship.

- Power Control consists of software necessary to operate the power system.

\section{ELECTRIC WARSHIP TECHNICAL ARCHITECTURE}

The Electric Warship Technical Architecture applies to electrical power systems for naval ships from concept exploration through delivery of the ship.

Figure 1 shows the relationships of the various technical documents. At the lowest level are commercial and military standards that provide rules, test requirements, best practices, and interface requirements. These standards are usually invoked through commercial and military specifications which collect all the requirements from the commercial and military standards in addition to equipment requirements into a document that can, along with owner preferences, be directly employed to buy power system components or equipment. These specifications can either be performance specifications which describe the equipment in terms of the performance, interfaces, and testing requirements, or detail specifications which specify the precise design for the equipment along with manufacturing methods and acceptance test procedures. The military standards and specifications should invoke commercial standards and specifications to the greatest extent practical. Military standards should only be used for military 
unique requirements, for those areas where no commercial standards exist, or for those areas where the Navy has deemed it beneficial to choose one or a few commercial standards to support where there are many commercial standards available. In some cases, a commercial specification may meet all naval requirements. In these cases, the Navy need only issue a letter of adoption of this commercial specification.

While the specifications are used to describe the requirements for procuring equipment, the processes for design and design verification are described in military handbooks and design data sheets. These Military handbooks and design data sheets should use existing documented commercial processes when applicable to naval ships. The Naval Combatant Design Specification (NCDS) describe requirements at the total ship and the ship system level for non-nuclear naval surface warships. The NCDS relies upon the military handbooks, specifications and standards in addition to design data sheets. These documents are not ship specific, and those that are important to the design and construction of electrical power systems are part of the electric warship technical architecture. This technical architecture is applied to the requirements for a specific ship to produce a ship design. The ship design and its systems architecture are captured in the ship specification.

\begin{tabular}{|c|c|c|c|}
\hline \multicolumn{3}{|c|}{$\begin{array}{l}\text { Ship Specifications } \\
\text { (ship unique) }\end{array}$} & \multirow[t]{2}{*}{$\begin{array}{l}\text { Systems } \\
\text { Architecture }\end{array}$} \\
\hline \multirow{3}{*}{ 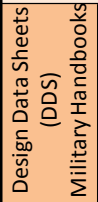 } & \multicolumn{2}{|c|}{$\begin{array}{l}\text { Naval Combatant Design Specification } \\
\text { (Naval Surface Ships in General) }\end{array}$} & \\
\hline & $\begin{array}{l}\text { Commercial Specifications } \\
\text { (common equipment) }\end{array}$ & $\begin{array}{l}\text { Military Specifications } \\
\text { (naval equipment) }\end{array}$ & \multirow[t]{2}{*}{$\begin{array}{l}\text { Technical } \\
\text { Architecture }\end{array}$} \\
\hline & $\begin{array}{l}\text { Commercial Standards } \\
\text { (common practices) }\end{array}$ & $\begin{array}{c}\text { Military Standards } \\
\text { (military environment) }\end{array}$ & \\
\hline
\end{tabular}

Figure 1. Technical Documentation Relationshipst

Technical documents for system design and for the specification of major power system equipment that are part of the electric warship technical architecture are listed in Appendix A. Note that appendix A does not include specifications for smaller components or for obsolete equipment that may still exist on ships in the fleet.

\section{STANDARDS DEVELOPMENT}

Figure 2 shows that specification and standard development should be an active consideration during the entire technology development process. In general, the specifications and standards should be viewed as one of the primary transition products. Additionally, it should be clear that complete specifications cannot be considered finished until a body of knowledge based on engineering and analysis is developed. The product of Advanced Technology Development and its Advanced Development Model (ADM) should be a draft generalized specification or standard (either commercial or military). This draft should be validated / updated through the successful procurement and testing of an Engineering Development Model (EDM). This specification or standard is transitioned to an acquisition program as either a formal specification or standard, or as a Project Peculiar Document (PPD) developed for incorporation into the ship specification. Eventually, if repeated procurements are anticipated, a specification or standard (commercial if possible, otherwise military), leveraging commercial specifications and standards, should be created.

While Figure 2 shows how specification and standards development should be incorporated into technology development programs, the realization of this process in existing programs has been weak. Explicitly addressing specification and standards development in Technology Transition Agreements could improve this process.

It is important to recognize that creating and maintaining specifications and standards has a real cost. This cost is an investment to ensure procured systems meet military requirements, reduce the cost of producing ship specifications, improve the quality of specification by reflecting lessons learned, and reducing rework by continuous incorporation of lessons learned in the specifications. Specifications and standards also enable industry to produce product lines in anticipation of Navy needs. Over-reliance on PPDs force industry to operate reactively to the Navy needs expressed at the time of the ship's detail design contract and may preclude the ability to offer the most affordable solutions.

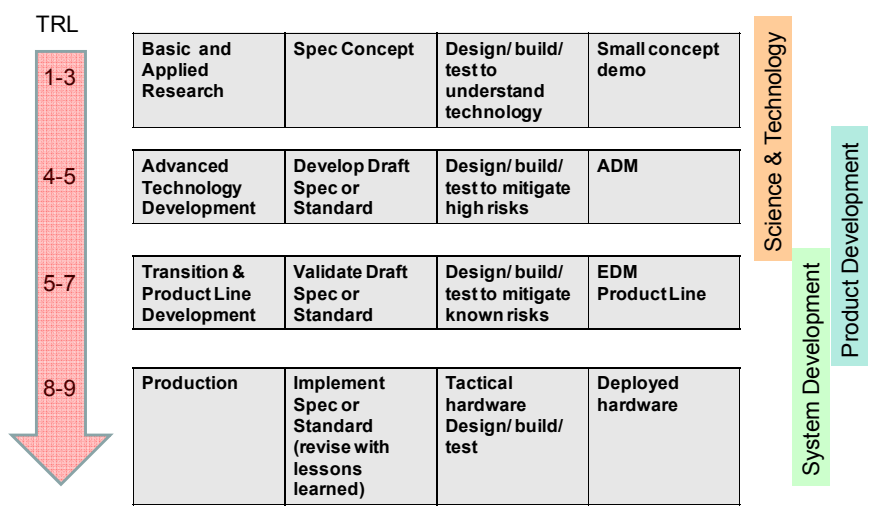

Figure 2. Technology Maturation and Product Development

\section{A. Military Technical Standards}

[2] provides the details for developing, revising, reviewing, approving, issuing, maintaining, canceling and adopting technical standards within NAVSEA. As managed by SEA 05S, the procedural steps for creating or revising a technical standard are:

a. Conduct Market Research. This may include conducting an Industry Day or issuing a Request for Information.

b. Determine whether a new standard, an update to an existing standard, or adoption of a nongovernment standard is warranted.

c. Initiate the project using a "Project Initiation Form" and a "Project Initiation Approval Request" (PIAR). In general the project initiation must be approved by the Technical Warrant Holder (TWH), the Deputy Warranting Officer (DWO), and the Standards Improvement Board (SIB). 
d. If funding is required, additional steps are required to gain approval to expend funds to complete the project

e. The document is updated or created, and approved by the TWH. (Note: A best practice is to involve industry and interested government stakeholders in the process)

f. SEA05S reviews the document and makes any necessary formatting or editorial changes to comply with established document requirements.

g. Document is circulated for Government and Industry Review. Comments are compiled into a tracking spreadsheet and adjudicated.

h. The final document is reviewed and approved by the SIB.

i. The final document is issued.

The Naval Sea Systems Command is currently reviewing and updating the many military specifications, standards, and handbooks under its responsibility. Where possible, the Navy employs commercial standards and specifications in an effort to reduce cost while maintaining military effectiveness. Military effectiveness in the varied environment that military systems must operate in must not be compromised.

\section{B. Commercial Standards}

A number of professional societies issue standards documents. For the electric warship, IEEE, IEC, NEMA, ASTM, SAE and API are likely to be the sources of most commercial standards used. The IEEE Standards Association manages the development of IEEE standards. Typical of commercial standards development, the process for creating / updating an IEEE standard as described in [3] is:

a. A sponsor is identified and a Project Authorization Request (PAR) is developed then approved by the IEEE-SA Standards Board.

b. Conduct meetings to develop the document, ensuring the meetings are open to all interested parties.

c. A standard "ballot" is conducted as part of the final review of the document.

d. If the "ballot" is successful, IEEE publishes the document.

\section{Incorporating the Electric Warship Technical Architecture into acquisition}

The ship specification and the associated Detail Design and Construction contract Statement of Work are the primary methods for incorporating the electric warship technical architecture into a ship acquisition program.

\section{ONGOING STANDARDS AND SPECIFICATION EFFORTS}

\section{A. Specifications}

MIL-DTL-XXXX Switchgear, Power, Medium Voltage, Naval Shipboard: initial development.

MIL-DTL-XXXX Circuit Breakers, VCB, Electric Power, Vacuum Medium Voltage, Draw-out Removable Construction, Without Internal Overcurrent Protection: initial development.

MIL-PRF-XXX, Protective Relays and Attachments for Use with Medium Voltage Vacuum Circuit Breakers: initial development.

MIL-DTL-917, (NAVY) Electric Power Equipment Basic Requirements is being modified to update referenced specifications and standards as well as incorporate changes to preserve military performance while enabling reductions in total ownership costs.

MIL-STD-1399 section 300B amendment to include: high resistance grounding for 450 VAC Type 1 power,. L-G voltage requirements, and power interruption requirements associated with QOS and survivability.

MIL-DTL-2212, Contactors and Controllers, Electric Motor AC or DC and Associated Switching Devices: general update.

MIL-DTL-3124, Generator, Alternating Current, 60 Hertz (Naval Shipboard Use): general update.

MIL-DTL-16036, Switchgear, Power, Low Voltage, Naval Shipboard: general update.

MIL-DTL-16377, Fixtures, Lighting, and Associated Parts, Shipboard use, General Specification for: general update including LED lighting.

MIL-DTL-17361, Circuit Breaker Types AQB,NQB, Air, Electric, Low Voltage, Insulated Housing (Shipboard Use), General Specification for: general update.

MIL-DTL-17587, Circuit Breakers, ACB, Low Voltage, Electric Power, Air, Removable Construction, General Specification for: general update.

MIL-DTL-17588, Breakers (Automatic -ALB-1) and Switch, Toggle (Circuit Breaker, Non-Automatic- NLB-1) Air, Insulated Housing, 125 Volts and Below A.C.: general update.

MIL-DTL-24643, Cables, Electric, Low Smoke HalogenFree, for shipboard Use, General Specification for: general update.

MIL-DTL-24765, Power Supply, Uninterruptible, Static (Naval Shipboard): general update.

MIL-PRF-32150 Static Automatic Bus Transfer Switch (SABT) on Surface and Submarine Naval Vessels: general update. 
MIL-PRF-32168 Variable Speed Drive System for Induction and Synchronous Machines. Revising to incorporate affordability initiatives.

MIL-PRF-32272 update to provide an open architecture definition for the individual modules comprising a Integrated Power Node Center (IPNC).

\section{B. Standards}

MIL-STD-X628, Design Criteria Standard for the Architecture of Machinery Control Systems: initial development.

MIL-STD-2037, Procedure to Obtain Certification for Electric Motor Sealed Insulation Systems, being reviewed for cancelation.

IEEE P45 Recommended Practices for Electrical Installations Shipboard: major update.

IEEE P45.1 Recommended Practice for Electrical Installations on Shipboard - Design: Initial development.

IEEE P45.3 Recommended Practice for Shipboard Electrical Installations - Systems Engineering: initial development.

IEEE P2030.4 Guide for Control and Automation Installations Applied to the Electric Power Infrastructure: Initial development.

IEEE P1580.1 Recommended Practice for Marine Insulated Bus Pipe (IBP) for Use on Shipboard and Fixed or Floating Platforms: initial development.

OPNAVINST 9300.yy Electrical Power Quality Requirements Program within the Department of the Navy: initial development.

NAVSEAINST 9304.1 Shipboard Electrical Cable and Cableway Inspection and Reporting Procedures: initial development.

\section{Handbooks and Design Data Sheets}

NSTM Chapter 300, Electric Plant - General: revision.

NAVSEA T9300-AF-PRO-020 Design Practices and Criteria Manual for Electrical Systems is being updated to reflect new technologies. Manual will reference DDS or Handbooks and provide tailoring guidance for commercial and military specifications and standards.

DDS 320-2 Electrical System Interface - Voltage and Current Harmonic Calculations: general update.

\section{RECOMMENDED FUTURE STANDARDS ACTIVITIES}

In the future standards activities should generally center on maturing the MVAC and ZEDS architectures as well as incorporating total ownership cost reduction initiatives in existing specifications and standards. The MVAC and ZEDS architectures can leverage specific platform specifications and lessons learned, including: LHD 8, T-AKE 1, DDG 1000, and other ships. Wherever possible commercial specifications and standards should be invoked. In some cases it may be possible to adopt commercial specifications and standards without having to create an accompanying military specification or standard to provide military unique requirements.

Standards and Specifications for MVDC applications require more development. Where reasonable, the requirements for MVDC applications should be folded into revisions of existing documents, minimizing the creation of new documents.

Commercial standards should be continuously evaluated for naval warship application.

\section{A. System Design and Engineering}

A new MIL-STD-1399 section for MVDC is needed.

A new MIL-STD-1399 section for LVDC is needed. DDG1000 and DDG51 specification efforts should be leveraged.

A new Standard (either military or commercial) for MVDC protection systems needed.

A new Design Data Sheets for stability analysis and module criteria allocation for each architecture with large power conversion components.

MIL-STD-2003A(SH) Electric Plant Installation Standard Methods for Surface Ships and Submarines requires updating to address MVDC.

\section{B. Power Generation}

MIL-R-2729D Military Specification: Regulator-Exciter Systems, Voltage, A.C. General, Naval Shipboard Use. General requires an update to ensure applicability to MVAC and MVDC systems. Alternately create a new specification that heavily leverages commercial standards.

MIL-G-21296B Generator Set, Diesel Engine, Direct and Alternating Current (Naval Shipboard Use): Consider a general update including incorporation of electronic governors, and allowance for magnetic bearings. Cover requirements for MVAC. Alternately create a new specification that heavily leverages commercial standards.

MIL-G-22077C: Generator Sets, Gas Turbine, Direct and Alternating Current, Naval Shipboard Use: Consider an update to cover Gas Turbine Generator Sets above 3,500 kW. Cover requirements for twin spool gas turbines. Cover requirements for MVAC. Alternately create a new specification that heavily leverages commercial standards.

MIL-M-24350B Monitors, Reverse Power and PowerSensing, Electrical Power (Naval Shipboard Use): Review for possible update for MVAC and MVDC. Alternately create a new specification that heavily leverages commercial standards.

A new Specification (either commercial or military) for Fuel Cell power generation needed.

Modifications to existing specifications needed to support MVDC architectures is needed.

A new Standard (either commercial or military) for MVDC voltage regulation and power sharing is needed. 


\section{Energy Storage}

A new performance specification (either commercial or military) for Energy Storage is needed.

\section{Power Distribution}

Update MIL-PRF-17773C Switches, Bus Transfer, Electric Power, Automatic and Manual to include functionality for a controllable bus transfer. Alternately create a new specification that heavily leverages commercial standards.

Update MIL-DTL-24643C Cables, Electric, Low Smoke Halogen-Free, for Shipboard use, General Specification for. Include Medium Voltage cables up to $20 \mathrm{kV}$ and cables for propulsion motors with high harmonic currents.

Consider developing Insulated Bus Pipe specification. Leverage IEEE P1580.1 IEEE Recommended Practice for Marine Insulated Bus Pipe (IBP) for Use on Shipboard and Fixed or Floating Platforms.

Consider creating a new specification for medium voltage transformers, Possibly extend MIL-T-15108C to include Medium Voltage applications.

Consider creating a new specification for three phase 450120VAC and 120-120 VAC three phase transformers. Possibly extend MIL-T-15108C to include 3 phase applications.

A new standard (either commercial or military) for MV shore power connections is needed.

\section{E. Power Conversion}

Extend MIL-PRF-32272 Integrated Power Node Center (IPNC) to include medium voltage input and higher power levels. Leverage ongoing medium voltage power conversion equipment developments.

\section{F. Propulsion Motors and Drives}

A new specification (either commercial or military) for Propulsion Motor and Drives is needed. Likely will invoke IEEE Std 1566-2005, IEEE Standards for Performance of Adjustable Speed AC Drives Rated 375 kW and Larger.

A new specification (either commercial or military) for forward retractable propulsion units is needed.

A new specification (either commercial or military) for podded propulsion units is needed.

\section{G. Power Control}

New specifications for Power Control Modules needed.

A new section of MIL-STD-1399 for machinery control system interface to loads needed.

A new handbook for describing the architecture and integration method for Power Control is needed.

\section{H. Other Technical Documents That Should Be Updated}

While these standards are not part of the Electric Warship Technical Architecture, the authors recommend they be updated to improve affordability and applicability to modern systems:

MIL-HDBK-217F Notice 2, Reliability Prediction of Electronic Equipment, of 28 Feb 1995: Consider including modern electronic and power devices.

MIL-STD-461F Requirements for the Control of Electromagnetic Interference Characteristics of Subsystems and Equipment of 10 Dec 2007: Consider updating to reflect what is affordably achievable for high power equipment provide common criteria for relaxing rules for power system elements. These criteria can either be incorporated in MILSTD-461F or contained in another document such as NCDS.

MIL-E-2036D(SH) Notice 2, Enclosures for Electric and Electronic Equipment of 29 October 2001.: To improve alignment with MIL-HDBK-2036 Preparation of Electronic Equipment Specifications, consideration should be given to referencing National Electrical Manufacturers Association (NEMA) specifications such as NEMA 250 Enclosures for Electrical Equipment (1000 Volts Maximum) and Underwriters Laboratory standards UL 50, UL 698, and ANSI/UL 1203. IEC Ingress Protection requirements should be reviewed to ensure appropriate minimum levels are invoked, especially in water-mist environments.

MIL-E-24142B Enclosures for Electrical Fittings and Fixtures, General Specification for of 17 Dec 1990 should be updated to reflect acceptable COTS products.

\section{CONCLUSION}

This paper described the electric warship technical architecture and the process for creating both military and commercial standards. The authors recommend that in the future, technology development programs should include as transition products the appropriate specifications and standards. A listing of documents currently part of the electric warship technical architecture are listed in Appendix A. This paper also provided the status of ongoing standards activities as well as future planned efforts.

\section{ACKNOWLEDGMENT}

The authors are thankful for and greatly appreciate the contributions of Nate Spivey in preparing this paper.

\section{REFERENCES}

[1] Naval Sea Systems Command, "NGIPS Technology Development Roadmap" NAVSEA Ser 05D / 349 of 30 Nov 2007.

[2] Naval Sea Systems Command, "NAVSEA TECHNICAL STANDARDS PROCEDURES," 30 Aug 2006.

[3] IEEE, "IEEE-SA Standards Board Operations Manual," December 2010.

Note: Military standards and specifications listed in this document are available from the online ASSIST database located at https://assist.daps.dla.mil. (The Quick Search feature does not require a login)

Copies of Design Data Sheets are available (subject to distribution statements) from Commander, Naval Sea Systems 
Command, ATTN: SEA 05S, 1333 Isaac Hull Avenue, SE, Stop 5160, Washington Navy Yard DC 20376-5160, or by email at CommandStandards@navy.mil with the subject line "DDS request" 


\section{APPENDIX A: EXISTING STANDARDS AND TECHNICAL DOCUMENTS}

\section{A. System Design and Engineering}

Standards

IEEE 1826-2012 IEEE Standard for Power Electronics Open System Interfaces in Zonal Electrical Distribution Systems rated above $100 \mathrm{~kW}$.

MIL-STD-1399 section 300B Electrical Power, Alternating Current, 24 April 2008.

MIL-STD-1399 section 680 High Voltage Electric Power, Alternating Current of 24 April 2008.

MIL-STD-2003A(SH) Electric Plant Installation Standard Methods for Surface Ships and Submarines of 3 September 2009.

NAVSEAINST 9300.1A Shipboard Alternating Current Electric Power of 28 Sep 1988.

\section{Handbooks and Design Data Sheets}

DDS 200-1 rev 1 Calculation of Surface Ship Endurance Fuel Requirements of 4 October 2011.

DDS 200-2 Calculation of Surface Ship Annual Energy Usage, Annual Energy Cost, and Fully Burdened Cost of Energy dated 7 August 2012.

DDS 310-1 rev 1 Electric Power Load Analysis (EPLA) for Surface Ships dated 17 Sept 2012.

DDS 320-2 Electrical system interface - voltage \& current harmonic calculations of 24 Feb 1988. 2012.

NSTM Chapter 300, Electric Plant-General, January 24,

NAVSEA T9300-AF-PRO-020 NAVSEA Design Practices and Criteria Manual Electrical Systems for Surface Ships Chapter 300, December 31, 1992.

\section{B. Power Generation}

\section{Specifications}

MIL-R-2729D, Military Specification: Regulator-Exciter Systems, Voltage, A.C. General, Naval Shipboard Use of 28 JAN 1992

MIL-G-3124D Notice 2, Generator, Alternating Current, 60-Hertz (Naval Shipboard Use) of 28 June 2007.

MIL-G-21296B Generator Set, Diesel Engine, Direct and Alternating Current (Naval Shipboard Use) of 21 Mar 1994.

MIL-G-21410A Military Specification, Governing Systems, Speed \& Load Sensing, Naval Shipboard Use of 23 December 1991.

MIL-G-22077C Generator Sets, Gas Turbine, Direct and Alternating Current, Naval Shipboard Use of 3 November 1993.
MIL-M-24350B NOTICE 2, Monitors, Reverse Power and Power-Sensing, Electrical Power (Naval Shipboard Use) of 11 February 2005.

\section{Handbooks and Design Data Sheets}

DDS 311-1 Frequency regulation of a.c. ship service electric power systems of 1 Dec 1970.

DDS 311-2 Voltage regulation of a.c. ship service electric power systems of 1 Oct 1972.

C. Energy Storage

Specifications

MIL-DTL-24765A Power Supply, Uninterruptible, Static (Naval Shipboard) of 26 April 2010.

\section{Standards}

DOD-STD-2134 Notice 1 - Storage Battery Arrangement for Minimum Stray Magnetic Field of 21 April 1989.

NAVSEAINST 9310.1B Naval Lithium Battery Safety Program, March 18, 2009.

\section{Handbooks and Design Data Sheets}

MIL-HDBK-2053 Requirements for Employing Standard Batteries of 18 January 1995.

\section{Power Distribution}

\section{Specifications}

MIL-DTL-915G - Cable, Electrical, for Shipboard Use, General Specification for, of 22 August 2002.

MIL-T-15108C, Transformers, Power, Step Down, Single Phase, 60 Hertz, 1 Kilovoltampere Approximate Minimum Rating, Dry Type, Naval Shipboard, of 20 Nov 1975.

MIL-DTL-16036L - Switchgear, Power, Low Voltage, Naval Shipboard, of 27 January2006.

MIL-DTL-17361G, Detail Specification: Circuit Breaker Types AQB/NQB, Air, Electric, Low Voltage, Insulated Housing (Shipboard Use), General Specification for, of 19 Sep 2006.

MIL-DTL-17587C, Circuit Breakers, ACB, Low Voltage, Electric Power, Air, Removable Construction, General Specification for, of 28 June 2007.

MIL-C-17588E Circuit Breakers (Automatic - ALB1) and Switch, Toggle (Circuit Breaker, non automatic NLB-1) Air, Insulated Housing, 125 volts \& Below, AC \& DC (Naval Shipboard Use) of 26 November 1985.

MIL-PRF-17773C(SH) Switches, Bus Transfer, Electric Power, Automatic and Manual, of 21 November 2006.

MIL-DTL-23928F, Panels, Electrical, Power Distribution and Manual Transfer, Circuit Breaker Type, of 26 June 2008. 
MIL-C-24368B Connector Assemblies; Plugs and Receptacles, Electric Power Transfer, Shore to Ship and Ship to Ship, General Specification for of 25 March 1987.

MIL-DTL-24640C Supplement 1 - Cable, Light-Weight, Electric, for Shipboard Use, General Specification for, of 8 Nov 2011.

MIL-DTL-24643C Cables, Electric, Low Smoke Halogen-Free, for Shipboard use, General Specification for, of 1 October 2009.

MIL-DTL-24705B, Penetrators, Multiple Cable, for Electric Cables, General Specification for, of August 23, 2010.

MIL-PRF-32150A Static Automatic Bus Transfer Switch (SABT) on Surface and Submarine Naval Vessels, of 7 June 2007.

\section{Standards}

MIL-STD-1683B, Design Criteria, Connectors and Jacketed Cable, Electric, Selection Standard for Shipboard Use of 31 March 1989.

MS18299, Shipboard Power Demand Factors 450 Volt, 7 April 1972 (Note: This has been incorporated into DDS 310-1 rev 1)

\section{Handbooks and Design Data Sheets}

MIL-HDBK-299 - Cable Comparison Handbook, Data Pertaining to Electrical Shipboard Cable of 15 Oct 1991.

DDS 300-2 Fault current calculations and protective device coordinations for 60 and $400 \mathrm{~Hz}$ power systems supplied by rotating machinery of 28 June 1995.

DDS 314-1 Calculations of fault currents and coordination of protective devices for $400 \mathrm{~Hz}$. Power systems supplied by solid state frequency changers of 21 June 1991.

\section{E. Power Conversion}

\section{Specifications}

MIL-T-15108C Transformers, Power, Step Down, Single Phase, 1 Kilovoltampere Approximate Minimum Rating, Dry Type, Naval Shipboard, of 3 Jul 1985.
MIL-PRF-32272 Integrated Power Node Center (IPNC) of 29 October 2007.

F. Loads

\section{Specifications}

MIL-DTL-2212J Contactors and Controllers, Electric Motor AC or DC, and Associated Switching Devices, of 22 Jan 2008.

MIL-DTL-16377H Fixtures, Lighting; and Associated Parts; Shipboard Use, General Specification for, of 2 Aug 1996.

MIL-DTL-17060G, Motors, Alternating Current, IntegralHorsepower Shipboard Use, of 8 Jan 2009

MIL-PRF-32168 Variable Speed Drive System for Induction and Synchronous Machines of July 27, 2004.

\section{Handbooks and Design Data Sheets}

DDS 302-1 Motor and controller application requirements (a.c. and d.c.) dated 3 May 1979 with replacement pages 1 and 20 of 4 Feb 1987.

\section{G. Power Control}

\section{Specifications}

MIL-PRF-32006 - Programmable Controller, Naval Shipboard, of 29 June 2004.

\section{Standards}

IEEE 45.2-2011 IEEE Recommended Practice for Electrical Installations on Shipboard - Controls and Automation of 1 Dec 2011.

IEEE 1676-2010 Guide for Control Architecture for High Power Electronics (1 MW and Greater) used in Electric Power Transmission and Distribution System of 11 February 2011. 